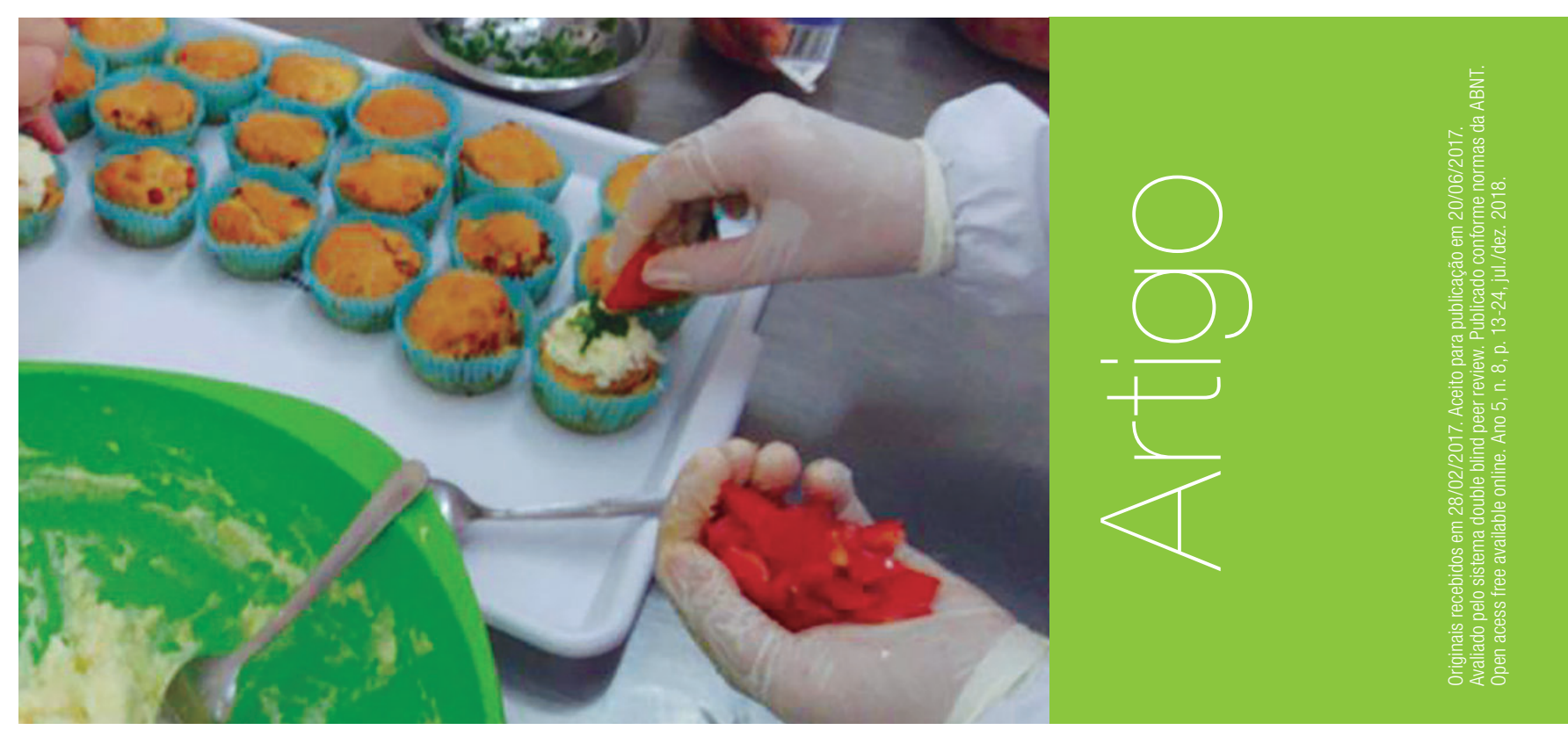

\title{
Formação em produção de alimentos: um fortalecimento das relações de inclusão social no Distrito do Passo Novo - Alegrete/ RS
}

\author{
Lidiane Moreira Chiattoni1 - lidiane.chiattoni@yahoo.com.br \\ Josiane Pasini² - josiane.pasini@bento.ifrs.edu.br \\ Yasmim Sena Vaz Leães ${ }^{3}$ - yasmimsvl@hotmail.com \\ Suzi Enéas Garcia Vilaverde ${ }^{4}$ - suzivilaverde@gmail.com
}

\section{RESUMO}

0 Brasil é um país rico em recursos naturais. Entretanto, há disparidade na distribuição dos mesmos, o que promove a desigualdade social. Faz-se necessário o desenvolvimento de projetos visando minimizar a fome e viabilizar a inclusão social do indivíduo, gerando renda e melhoria da qualidade de vida. 0 objetivo deste trabalho é apresentar um relato de extensão que promoveu um curso de Formação Inicial e Continuada em Masseiro, direcionado às produtoras rurais da Vila do Passo Novo e dos Assentamentos Novo Alegrete e Unidos pela Terra - Alegrete/RS.

\footnotetext{
1 Doutora em Engenharia e Ciência de Alimentos - Universidade Federal do Rio Grande. Professora da Faculdade Anhanguera Câmpus São José-SC.

2 Mestra em Fitotecnia - Universidade Federal do Rio Grande do Sul. Professora do EBTT no Instituto Federal do Rio Grande do Sul - Câmpus Bento Gonçalves.

3 Tecnóloga em Agroindústria - Instituto Federal Câmpus Alegrete. Mestranda em Ciência e Tecnologia dos Alimentos Universidade Federal de Santa Maria.

4 Tecnóloga em Agroindústria Instituto Federal Farroupilha Câmpus Alegrete.
} 
Participaram do curso, realizado nas dependências do IFFar - Câmpus Alegrete, 40 mulheres. Verificou-se que, através de ações como esta, é possivel transformar a realidade de comunidades e propiciar sua inclusão na sociedade, bem como expandir as atividades do meio acadêmico.

\section{PALAVRAS-CHAVE}

Ações de extensão. Panificação. Qualidade de vida.

\section{ABSTRACT}

Brazil is a rich country in natural resources, however, there is a disparity in the distribution of these, which promotes social inequality. It is necessary to develop projects to minimize hunger and enable the social inclusion of the individual, generating income and improving the life quality. The objective of this work is to present the activities of the extension project that promoted a Initial and Continuing Training Coursein bakery products directed to the rural producers from Vila do Passo Novo and Novo Alegrete and Unidos pela Terra settlements - Alegrete/RS. A total of 40 women participated in the course, held in the premises of the IFFar - Campus Alegrete. It was verified that through actions like this one, it is possible to transform reality of communities and to promote their inclusion in society, as well as to expand the activities of the academia.

\section{KEYWORDS}

Extension actions. Bakery. Quality of life.

\section{Introdução}

Segundo Calgaro, Alfonso e Araújo (2013), para acabar com a fome no Brasil, faz-se necessária a garantia ao acesso de toda a população, em todo o momento, a alimentos nutritivos e seguros, em quantidade suficiente para uma vida ativa, saudável e garantindo a segurança alimentar. Deve haver uma intensificação dos esforços para atingir a mesma e assim acabar com a fome e a desnutrição, junto com suas consequências, para as gerações atuais e futuras. 0 aproveitamento total de alimentos atua no âmbito familiar, promovendo benefícios para a própria família, aumentando a variedade de alimentos nas refeições e contribuindo para 0 incremento da dieta nutritiva e saudável.

A produção para 0 autoconsumo designa a satisfação das necessidades de um determinado indivíduo ou grupo familiar através da utilização de produtos ou serviços produzidos por ele próprio. Na agricultura familiar, traduz-se especialmente pela diversidade da produção de alimentos, originados dos sistemas de obtenção que visam satisfazer as necessidades alimentares de subsistência dos agricultores e de suas famílias, embora nem todos os alimentos indispensáveis possam ser produzidos pela família, o que permite estabelecer relações com os mercados através da comercialização de parte da produção (GRISA, 2007).

0 pão é um gênero alimentício de primeira necessidade e, ao longo dos séculos, os padeiros artesãos de todo o mundo desenvolveram as tradicionais variedades de pães, utilizando seu conhecimento acumulado sobre como empregar, da melhor maneira possível, as matériasprimas disponíveis para obter a qualidade desejada. Em geral, isso ocorreu pela adaptação e pelas mudanças das técnicas de fabricação pré-existentes. Hoje em dia, o estudo científico e o desenvolvimento técnico proporcionam maneiras mais rápidas e de melhor custo-benefício para a sua fabricação, levando-se também em consideração novas matérias-primas disponíveis e os métodos de fabricação, satisfazendo a demanda dos clientes por produtos fermentados frescos, saudáveis e saborosos (CAUVAIN, 2009). Segundo levantamento realizado pelo Instituto Tecnológico de Panificação e Confeitaria (ITPC) em parceria com a Associação Brasileira da Indústria de Panificação e Confeitaria (ABIP) realizado em mais de 400 empresas de todo o país, abrangendo representantes de todos os portes, registrou-se um crescimento no setor de 3,08\% em 2016, o que equivale a um faturamento de $R \$ 87,24$ bilhões (ABIP, 2018).

Projetos que visem minimizar a fome e viabilizar a inclusão social do indivíduo é o grande desafio de muitos países, como o Brasil, onde a miséria e a pobreza atingem grande parte da população, 
deixando-a excluída e em estado de vulnerabilidade social. Apesar de rico em recursos naturais que podem ser utilizados para a alimentação humana, o Brasil os utiliza pouco, bem como não orienta sua população em relação às formas de exploração. De acordo com o trabalho de Witt e Souza (2016), apesar de atualmente existir o "Plano Brasil sem Miséria", conjunto de ações que consolidam as políticas públicas e diretrizes governamentais de inclusão educacional, social e produtiva de mulheres em situação de vulnerabilidade no Brasil, no período entre 2011 e 2013, o "Programa Mulheres Mil" no IFSC verificou que mulheres poderiam ser excluídas da oferta via Progama Nacional de Acesso ao Ensino Técnico e Emprego - Pronatec em função do perfil de baixa escolaridade.

Dessa forma, o objetivo do presente estudo é apresentar o relato de atividades de extensão, como 0 curso de Formação Inicial e Continuada (FIC) em Masseiro e oficinas de capacitação em diversos temas para mulheres em situação de vulnerabilidade social da Vila do Passo Novo e dos Assentamentos Novo Alegrete e Unidos pela Terra, localizados na cidade de Alegrete/RS, com vistas ao autoconsumo, segurança alimentar da família, geração de renda e melhoria da qualidade de vida.

\section{Metodologia}

\subsection{Equipe de trabalho e local de execução das atividades de extensão}

Para realização das atividades, houve engajamento de 14 docentes das mais diversas áreas (Segurança do Trabalho, Tecnologia de Alimentos, Química Ambiental, Administração, Medicina Veterinária, entre outras), 3 técnicos (médico, assistente social, psicólogo), 10 alunos do curso superior em Agroindústria e 2 do curso técnico em Agroindústria - modalidade Proeja do Instituto Federal Farroupilha - Campus Alegrete, situado na rodovia RS 277, s/n, Passo Novo, Alegrete/ RS. 0 curso FIC foi realizado no Laboratório de Ensino, Pesquisa e Extensão em Panificação (LEPEP - Panificação) e as oficinas em salas de aula da instituição de ensino.

\subsection{Descrição da comunidade}

A escolha das comunidades rurais para a realização da ação de extensão foi embasada na demanda potencial existente, tendo em vista as áreas de produção da agricultura familiar e os assentamentos da reforma agrária. Cerca de $35 \mathrm{~km}$ longe do centro da cidade de Alegrete/RS, o distrito do Passo Novo, também conhecido como "Vila de Passo Novo", possui cerca de 2.800 famílias, e os assentamentos são compostos por cerca de 100 famílias, que se sustentam pela agricultura familiar e se utilizam da sua produção para alimentação (IBGE, 2018). Os assentamentos da reforma agrária Novo Alegrete e Unidos pela Terra, distantes cerca de $15 \mathrm{~km}$ do distrito, dedicam-se, assim como a Vila do Passo novo, às atividades agropecuárias, como fruticultura, olericultura, gado leiteiro, ovinocultura e gado de corte.

\subsection{Evento de socialização}

Inicialmente foi realizado na Escola Barros Cassal, localizada no distrito do Passo Novo - Alegrete, um evento de socialização e divulgação do projeto "Formação em produção de alimentos: um fortalecimento das relações de inclusão social no Distrito do Passo Novo - Alegrete/ RS". Nesse dia, professores e alunos bolsistas e voluntários, em parceria com a Associação Tabatinga de Usuários Familiares Amigos da Saúde Mental da Vila do Passo Novo e com os Assentamentos Novo Alegrete e Unidos pela Terra, explanaram os objetivos, metodologia e cronograma da proposta para a comunidade. 


\subsection{Seleção do público beneficiado}

Na comunidade do distrito do Passo Novo e dos assentamentos ali situados, as mulheres comumente são as responsáveis pela produção dos alimentos e das refeições servidas diariamente na família. Além da aprendizagem das técnicas de produção e higienização dos alimentos, 0 excedente da produção pode ser utilizado para a comercialização na própria comunidade e para auxiliar no aumento da renda da família. Sendo assim, o público alvo da atividade de extensão foi mulheres da comunidade com baixa escolaridade e renda.

\subsubsection{Identificação de interesse pelo curso FIC}

No dia da socialização, houve a identificação das mulheres interessadas em participar do curso FIC. A seleção foi baseada na quantidade de pessoas a serem comportadas na LEPEP Panificação, bem como idade, escolaridade e situação financeira das mulheres.

\subsubsection{Identificação de interesse pelas oficinas}

Junto ao evento de socialização, foi identificado o público interessado em participar das oficinas a serem ministradas por uma equipe multidisciplinar, composta por servidores do IFFar - Campus Alegrete. A seleção foi baseada na idade, escolaridade e situação financeira das mulheres. Como o número de mulheres interessadas foi menor que a quantidade comportada pelas salas de aula, algumas oficinas foram disponibilizadas também para o público masculino.

\subsection{Realização das atividades de capacitação}

Para facilitar a participação, um ônibus fretado pela instituição realizou o deslocamento dos participantes entre a comunidade atendida e 0 local de execução das atividades. 0 curso FIC foi realizado no período de junho a novembro de 2016, sendo distribuído em aulas práticas/ teóricas semanais (4h cada) sobre Produção de Alimentos Panificáveis, totalizando 160h. Já as oficinas ocorreram entre os meses de agosto e novembro de 2016, contemplando um total de 40h, as quais desenvolveram os seguintes temas: "Segurança dos alimentos" (12h); "0 papel da associação em uma comunidade" (12h); "Segurança do trabalho e gestão de resíduos" (12h) e "0 bem estar da mulher no ambiente do lar" (8h). Esta última foi direcionada somente às mulheres.

Durante a execução do projeto, houve o controle de presença através de lista de assinaturas e entrega de material instrutivo. Ao final do curso FIC, bem como de cada oficina, os participantes responderam a um questionário adaptado para cada capacitação. No mês de novembro foi realizado 0 evento de encerramento do projeto. Neste dia houve uma confraternização final, divulgação dos resultados atingidos e certificação aos participantes do curso FIC.

\section{Resultados e Discussão}

\subsection{Identificação do público beneficiado}

A LEPEP de Panificação do IFFar Câmpus Alegrete comporta 40 pessoas. Deste modo, 40 mulheres, com idade entre 18 e 75 anos, cadastradas em algum tipo de benefício social do Governo Federal, foram inscritas no curso FIC. Do total, 39 se mantiveram presentes até 0 final das atividades. Participaram das oficinas de extensão 40 pessoas da comunidade, sendo 36 do sexo feminino.

Cerca de 96\% das famílias do Distrito e dos Assentamentos são beneficiárias de programas sociais. Em relação à renda familiar, de acordo com os dados levantados, 59\% das famílias possuem renda inferior a meio salário mínimo, ou seja, têm como principal renda os benefícios sociais adquiridos. 0 desemprego também assombra os moradores da Vila do Passo Novo, uma vez que $80 \%$ dos responsáveis pelos domicílios estão nessa situação. A subsistência da família provém dos benefícios assistenciais e da produção própria de alimentos. Estes dados foram 
fornecidos pela Escola Estadual de Ensino Fundamental Barros Cassal, que possui contato direto com as famílias e coletam dados da comunidade por terem alunos oriundos desses locais e com o Centro de Referência em Assistência Social (CRAS), vinculado à Secretaria de Promoção e Desenvolvimento Social do município de Alegrete/ RS, que atendem essas comunidades.

\subsection{Produção da atividade de capacitação}

Ao longo da ação de extensão, as participantes tiveram contato direto com a produção de massas caseiras, pães e biscoitos tradicionais e funcionais, além de produtos de confeitaria como bolos, tortas e doces de festa. Abaixo, nas Figuras 1 a 12, pode-se visualizar algumas das atividades promovidas durante 0 curso FIC.

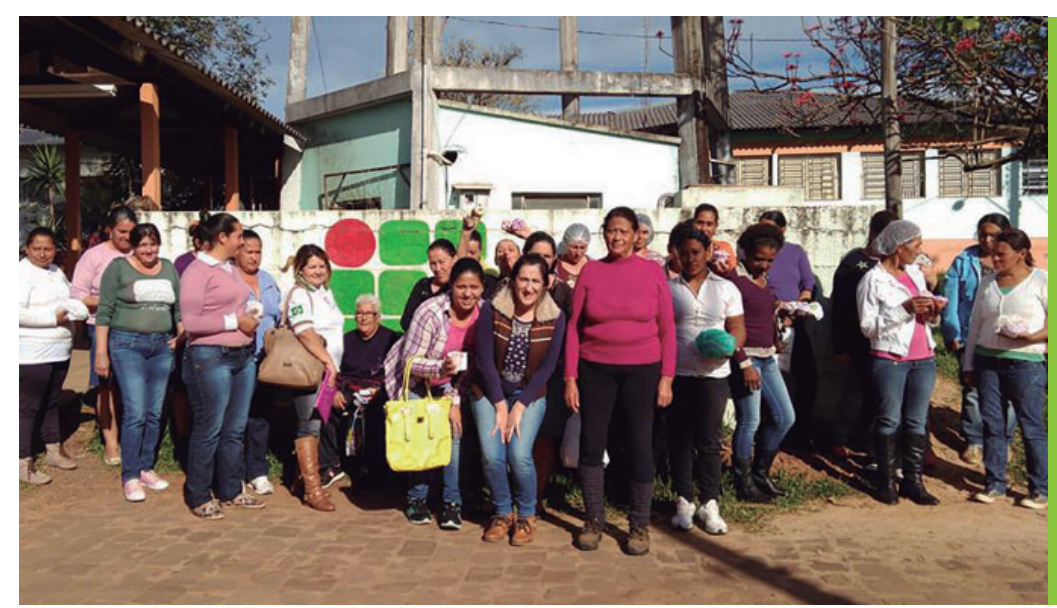

Figura 1: Integrantes do curso FIC no primeiro dia de a Fonte: Dados desta Pesquisa.

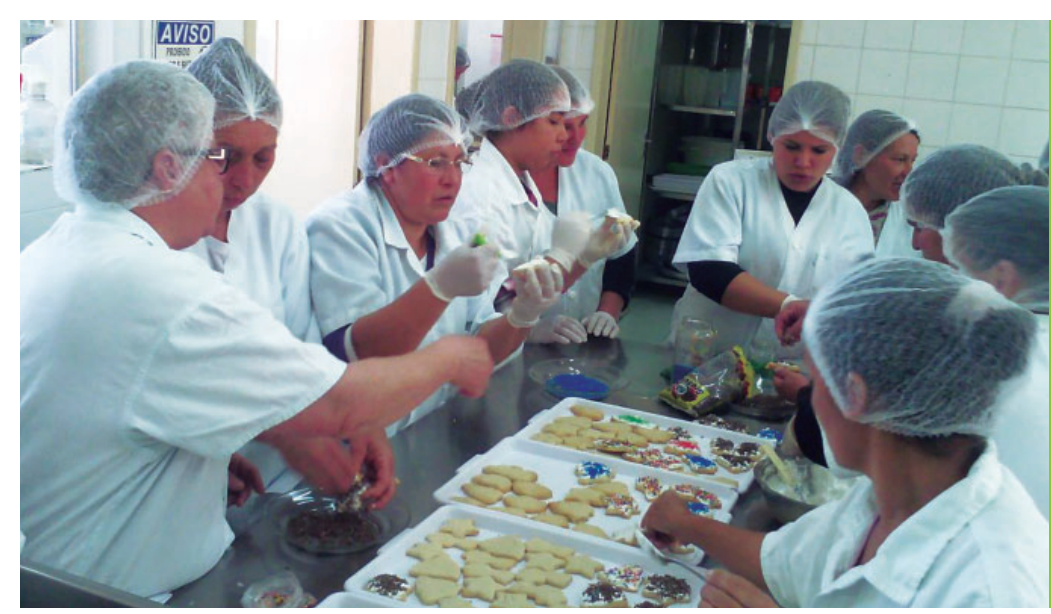

Figura 2: Produção de biscoitos.

Fonte: Dados desta Pesquisa.

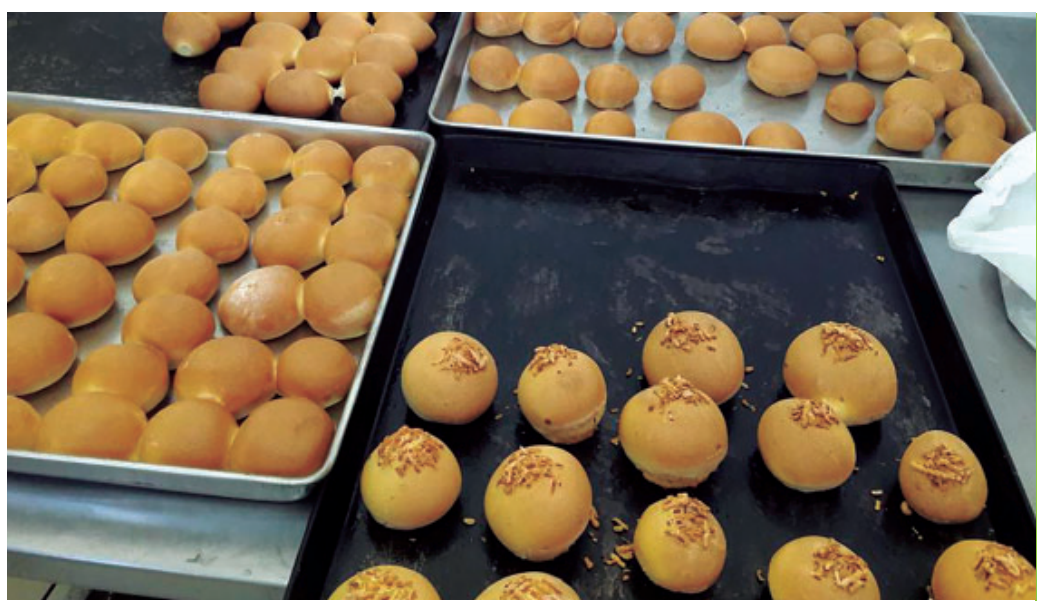

Figura 3: Produção de pães.

Fonte: Dados desta Pesquisa. 
Figura 4: Produção de bolos. Fonte: Dados desta Pesquisa.

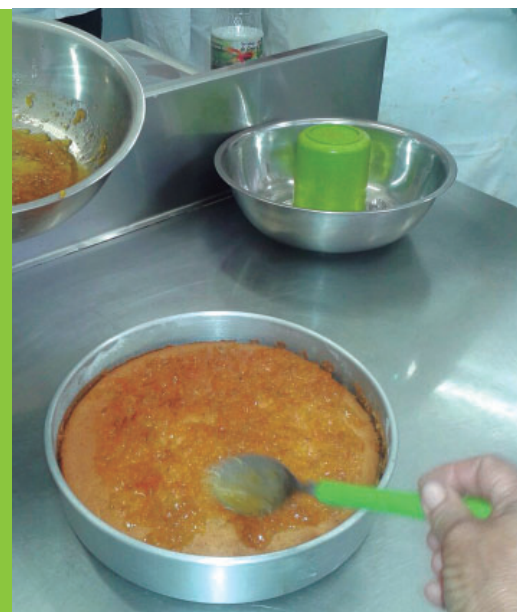

Figura 5: Produção de bolos decorados. Fonte: Dados desta Pesquisa.

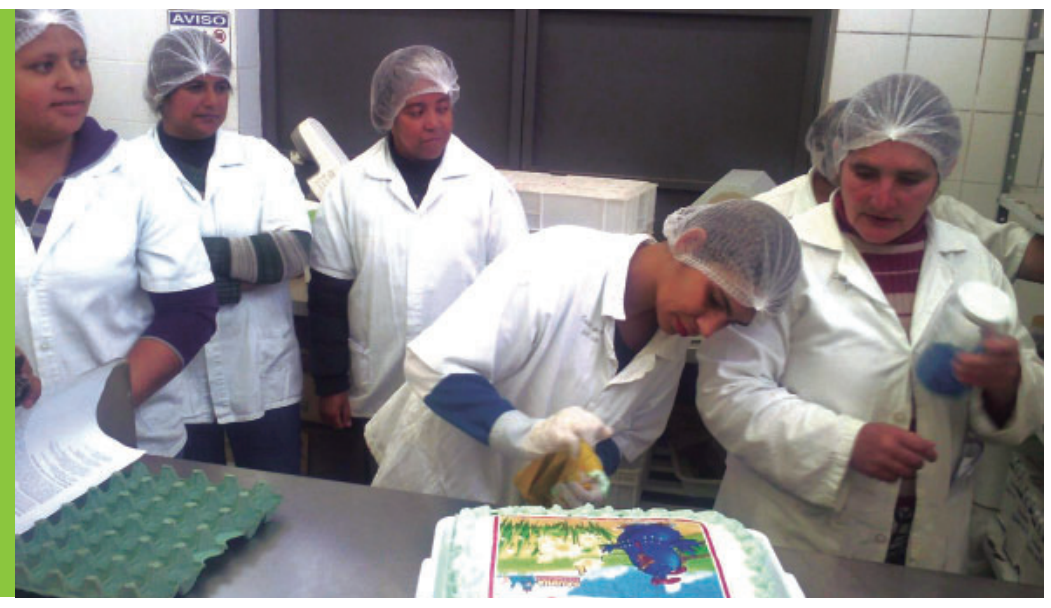

Figura 6: Produção de recheios e coberturas.

Fonte: Dados desta Pesquisa.

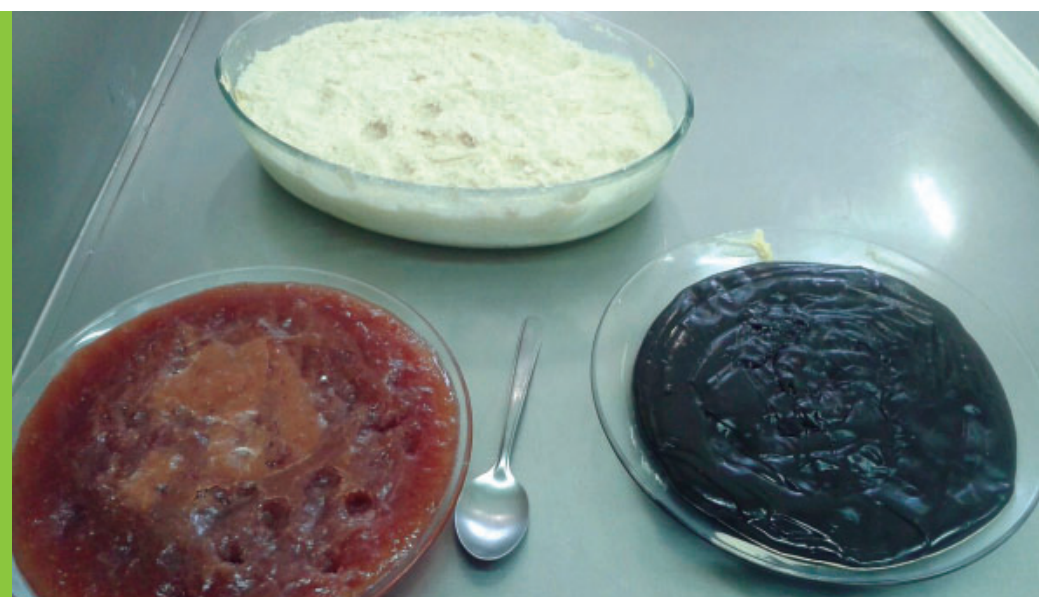

Figura 7: Produção de doces festivos.

Fonte: Dados desta Pesquisa.

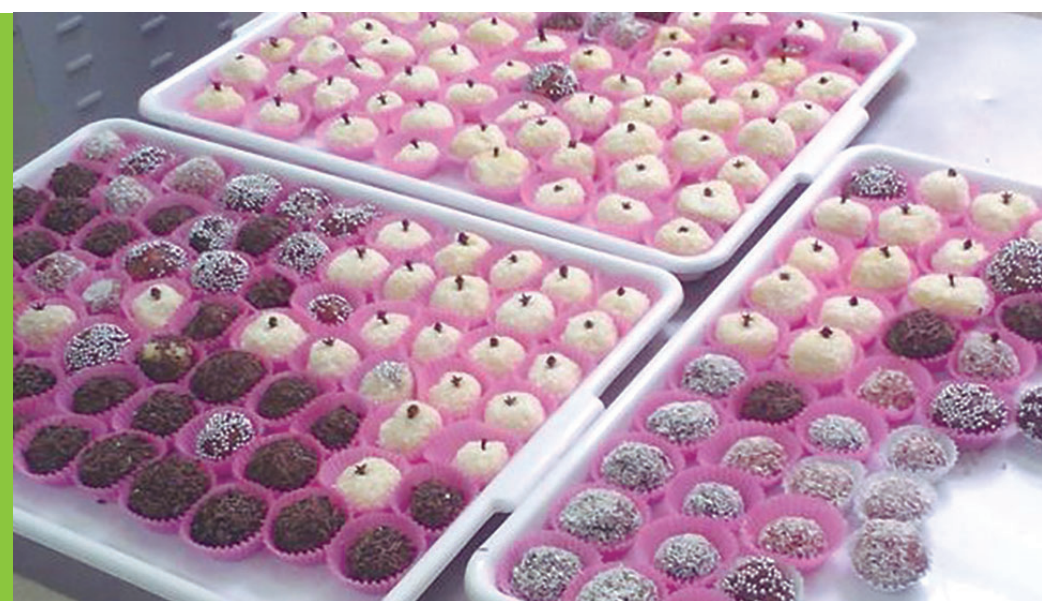




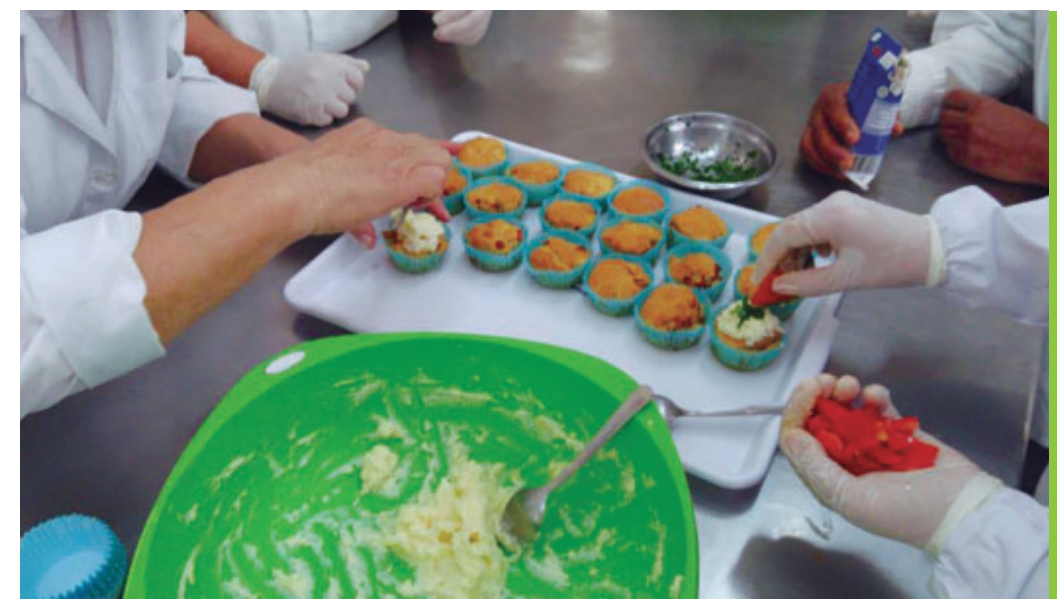

Figura 8: Produção de cupcakes.

Fonte: Dados desta Pesquisa.

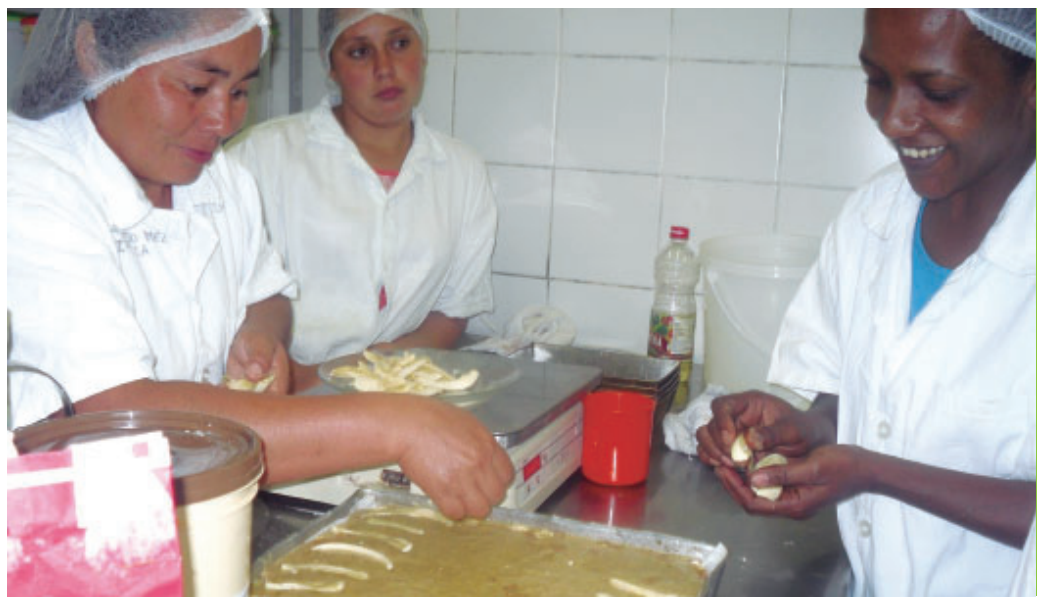

Figura 9: Produção de cucas.

Fonte: Dados desta Pesquisa.

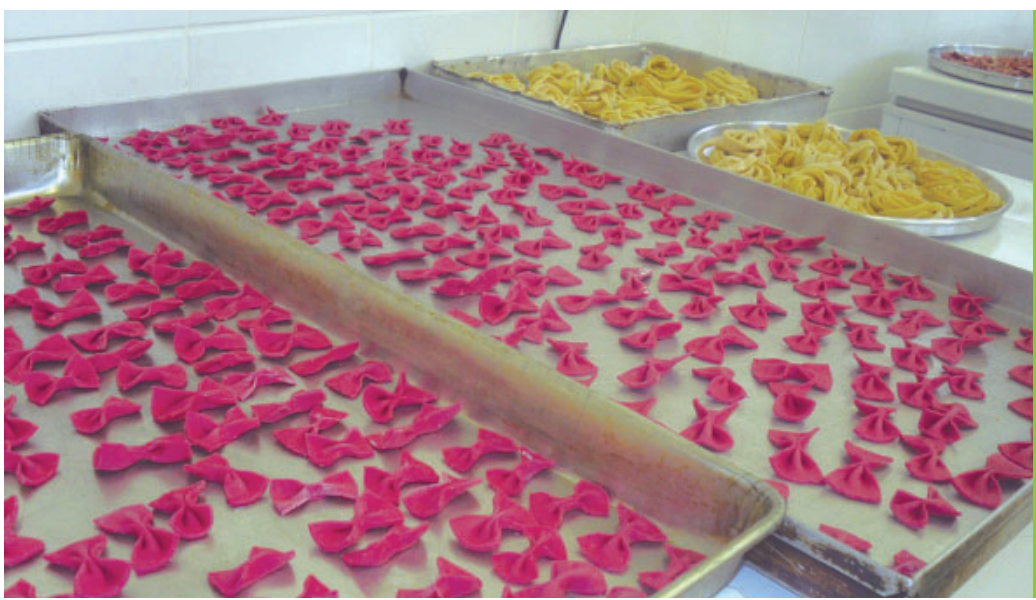

Figura 10: Produção de massas frescas.

Fonte: Dados desta Pesquisa.

Figura 11: Produção de massas e

molhos para pizzas.

Fonte: Dados desta Pesquisa. 
Figura 7: Produção de frios.

Fonte: Dados desta Pesquisa.

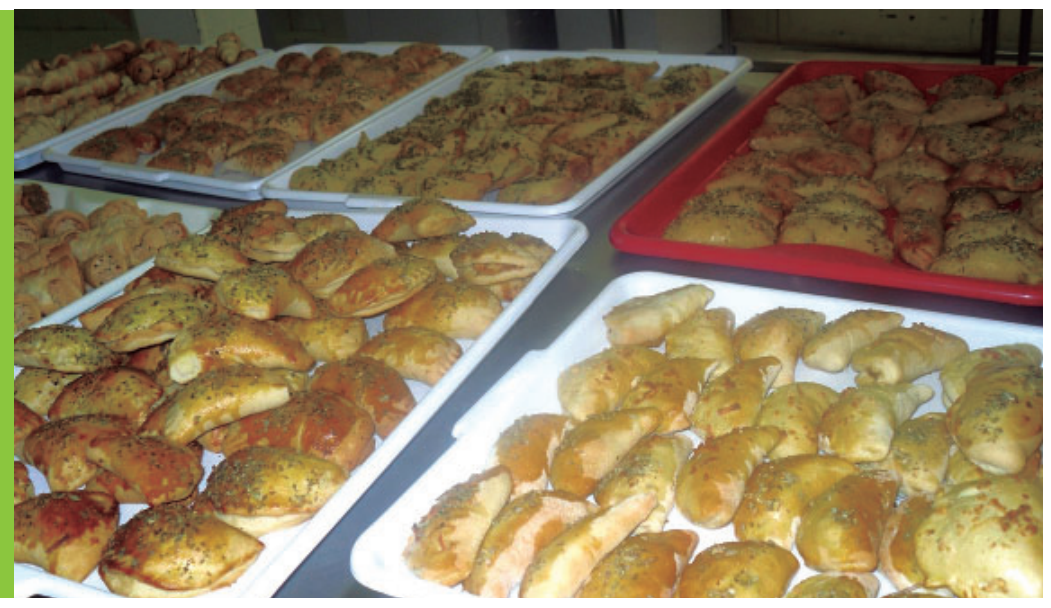

\subsection{Encerramento e avaliação das atividades de extensão}

Na Tabela 1, estão expressas as respostas das 39 alunas participantes do curso FIC quanto ao grau de satisfação do curso, em forma de porcentagem.

Tabela 1: Respostas obtidas através da ficha de avaliação do FIC de Masseiro.

Fonte: As autoras, 2017. Observação: as notas "péssimo" e fraco não foram dadas pelas alunas.

\begin{tabular}{lccc}
\hline Item & \multicolumn{3}{c}{$\%$} \\
\hline & MÉDIO & BOM & EXCELENTE \\
\hline Divulgação do curso & 25 & 70 & 5 \\
Programação do curso & - & 5 & 95 \\
Organização do curso & - & - & 100 \\
Temas abordados no curso & - & - & 100 \\
Conhecimento dos professores em relação ao tema & - & - & 100 \\
Data e horário de realização do curso & - & 30 & 70 \\
\hline
\end{tabular}

Foi solicitado às alunas, ainda, que relatassem e/ou realizassem sugestões acerca do curso. Em relação aos relatos ao final da capacitação, a grande maioria se demonstrou satisfeita com a aprendizagem adquirida. Pode-se destacar: “...excelentes professores e alunas. Não tenho palavras para agradecer este curso divino e maravilhoso. Peço em meu nome que em 2017 tenha outro."

"O curso foi um ótimo desenvolvimento de criatividade e aprendemos muito." "É um meio de colocarmos em prática as experiências que aprendemos e temos a oportunidade de aumentar a renda familiar."

"Aprendemos a manipular alimentos que são fantásticos para fazermos para o comércio e para a família."

"É um curso para uso doméstico ou industrial."

"Sugiro que ao longo do tempo possamos ter novas oportunidades de estar no IFFar para novos cursos e oficinas, pois nos ajuda muito."

"Muito obrigado a todas as pessoas que nos proporcionaram esta oportunidade e parabéns a todos os envolvidos."

Quanto às oficinas, os participantes se mostraram emocionados e agradecidos pelos conhecimentos adquiridos e pela oportunidade de trocarem experiências nas suas comunidades (Quadro 1). 


\begin{tabular}{|c|c|}
\hline OFICINA & $\begin{array}{l}\text { QUAIS OS PONTOS POSITIVOS OU NEGATIVOS E } \\
\text { SUGESTÕES SOBRE A OFICINA? }\end{array}$ \\
\hline $\begin{array}{l}\text { Segurança dos alimentos (12h) } \\
\text { Ministrada pelos servidores: Nádia Hermel } \\
\text { Gobbi; Paulo Duran dos Santos Molina; Patricia } \\
\text { Alessandra Meneguzzi Metz Donicht. }\end{array}$ & $\begin{array}{l}\text { "Serviu para ter melhor conhecimento tanto no lar como } \\
\text { com o que forneceremos a outras pessoas." "Para ter um } \\
\text { melhor conhecimento profissional e poder comercializar } \\
\text { os produtos produzidos por mim.." "Melhorou meu } \\
\text { aprendizado sobre cuidados de higiene." "Está sendo muito } \\
\text { bom porque através do dialogo a gente aprende muito." }\end{array}$ \\
\hline $\begin{array}{l}\text { O papel da associação em uma } \\
\text { comunidade (12h) } \\
\text { Ministrada pelos servidores: Suelen Deleal } \\
\text { Rodrigues; Vinicius Radetzke da Silva. }\end{array}$ & $\begin{array}{l}\text { "Foi muito bom aprendi e tirei minhas dúvidas, e a } \\
\text { apresentação estava excelente." "Em minha opinião } \\
\text { foi tudo bem explicado e de bom entendimento." "Que } \\
\text { sempre tenhamos mais oportunidade de mais oficinas e } \\
\text { curso como este, está tudo bom e só tenho a agradecer." }\end{array}$ \\
\hline $\begin{array}{l}\text { Segurança do trabalho e gestão de } \\
\text { resíduos (12h) } \\
\text { Ministrada pelos servidores: Alex Leal de } \\
\text { Oliveira; Keylla Pedroso. }\end{array}$ & $\begin{array}{l}\text { "Professores ótimos e os temas abordados foram } \\
\text { satisfatoriamente entendidos por todos." "A oficina foi de } \\
\text { grande aproveitamento pra nós que participamos desta } \\
\text { oficina, pois o tema abordado pelos professores nos trouxe } \\
\text { bons ensinamentos que vamos usar no nosso dia a dia." } \\
\text { "As oficinas serviram para nos esclarecer muitas dúvidas, } \\
\text { melhorou nossos conhecimentos além da integração que } \\
\text { tivemos com outras pessoas." }\end{array}$ \\
\hline $\begin{array}{l}0 \text { bem-estar da mulher no ambiente do } \\
\text { lar (8h) } \\
\text { Ministrada pelos servidores: Anderson Flores; } \\
\text { Denise Margareth Borges Ancini; Evelise Freire de } \\
\text { Azambuja dos Reis; Luciana de Oliveira Fortes. }\end{array}$ & $\begin{array}{l}\text { "Nós moramos longe da cidade e é de grande importância } \\
\text { que alguém venha nos relatar temas de muito valor, como } \\
\text { por exemplo, o câncer de colo do útero" } \\
\text { "Que sempre tenhamos mais oportunidade de mais oficinas } \\
\text { e curso como este, está tudo bom e só tenho a agradecer." }\end{array}$ \\
\hline
\end{tabular}

Quadro 1: Relatos dos participantes sobre as oficinas de extensão.

As Figuras 13 a 15 mostram algumas das atividades promovidas através das oficinas realizadas com o público alvo.

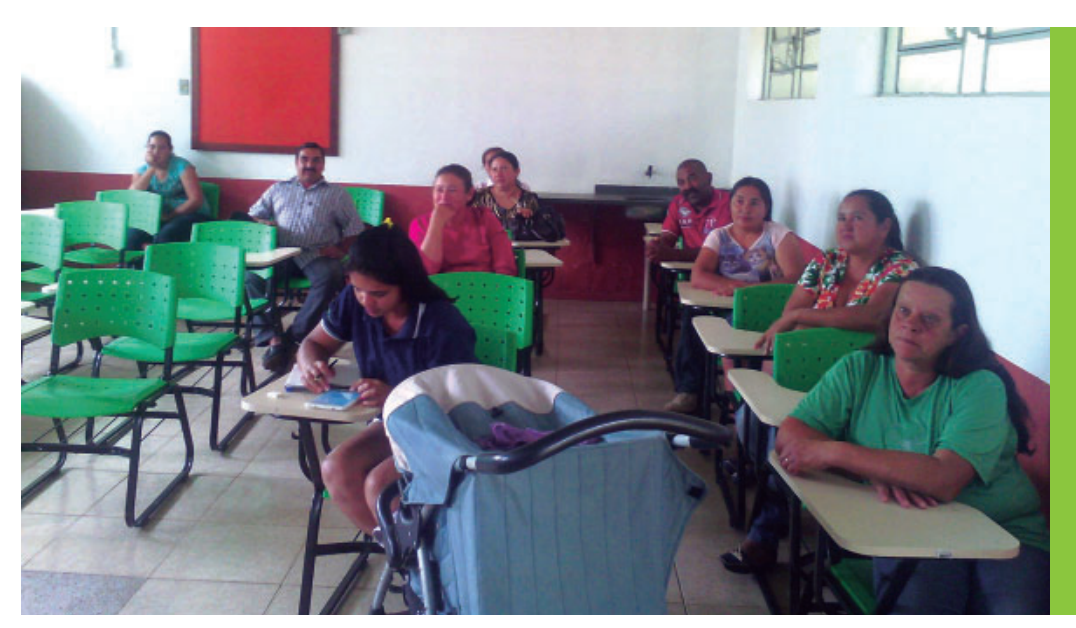

Figura 13: Alunos durante a Oficina "Segurança dos alimentos".

Fonte: Dados desta Pesquisa.

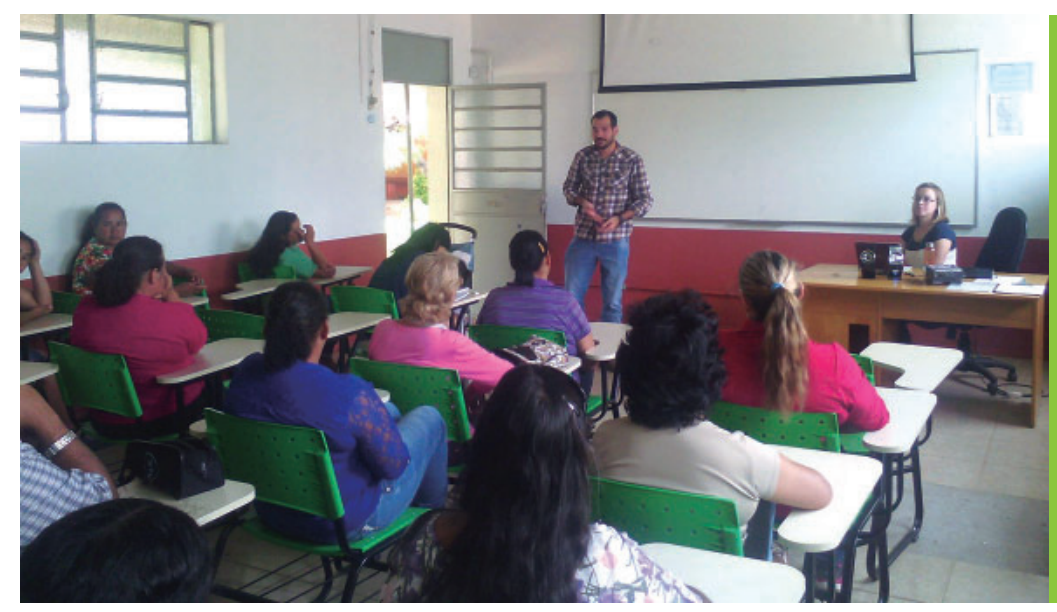

Figura 14: Alunos durante a Oficina "Segurança do trabalho e gestão de resíduos".

Fonte: Dados desta Pesquisa. 
Figura 15: Alunos durante a Oficina

"Segurança do trabalho", na Planta

de Panificação, sendo abordados os perigos e os cuidados quanto ao uso de equipamentos e utensílios.

Fonte: Dados desta Pesquisa.

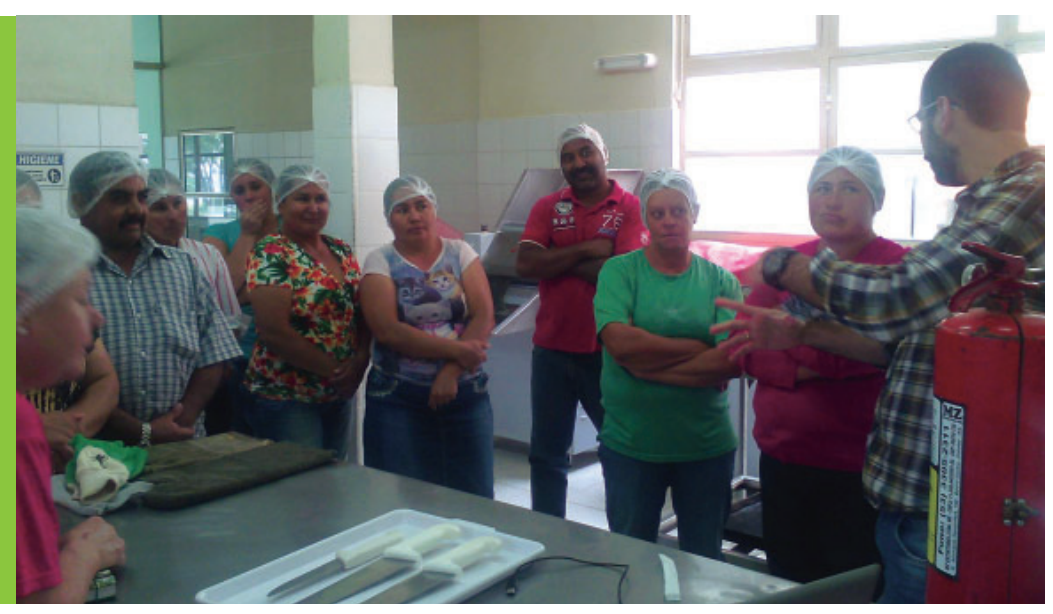

Ao finalizar o curso e após verificação dos alunos com frequência superior a $75 \%$, foi realizado um evento de confraternização com lanche preparado pelos alunos do Instituto Federal Farroupilha Câmpus Alegrete. Neste dia houve entrega de certificados ao público atendido (Figuras 16 a 19).3.4 Contribuições da atividade de extensão

Figura 16: Parte da equipe de docentes envolvidos na execução do projeto.

Fonte: Dados desta Pesquisa.

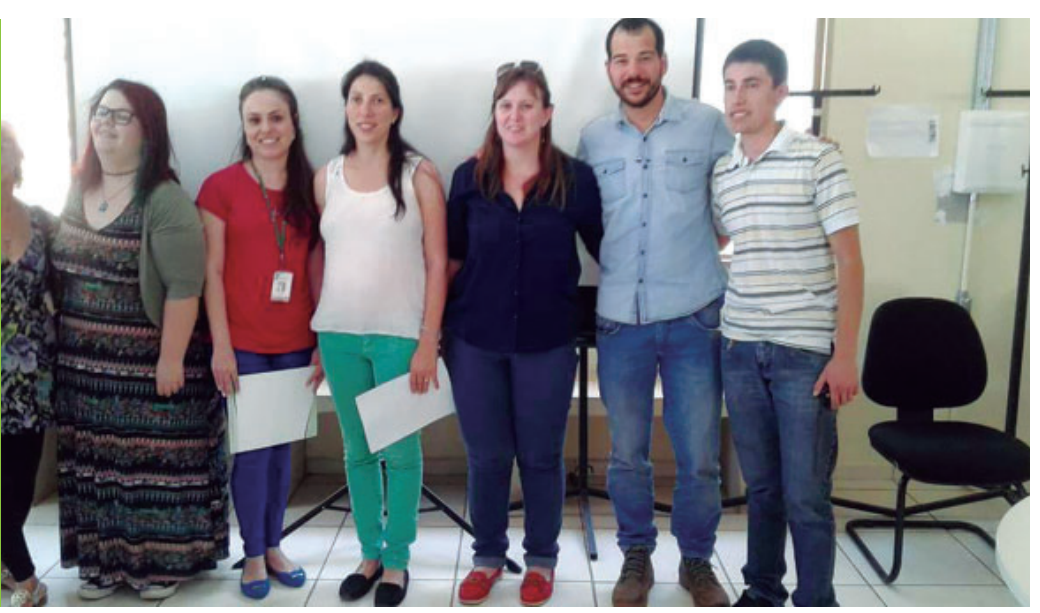

Figura 17: Evento de finalização e certificação.

Fonte: Dados desta Pesquisa.

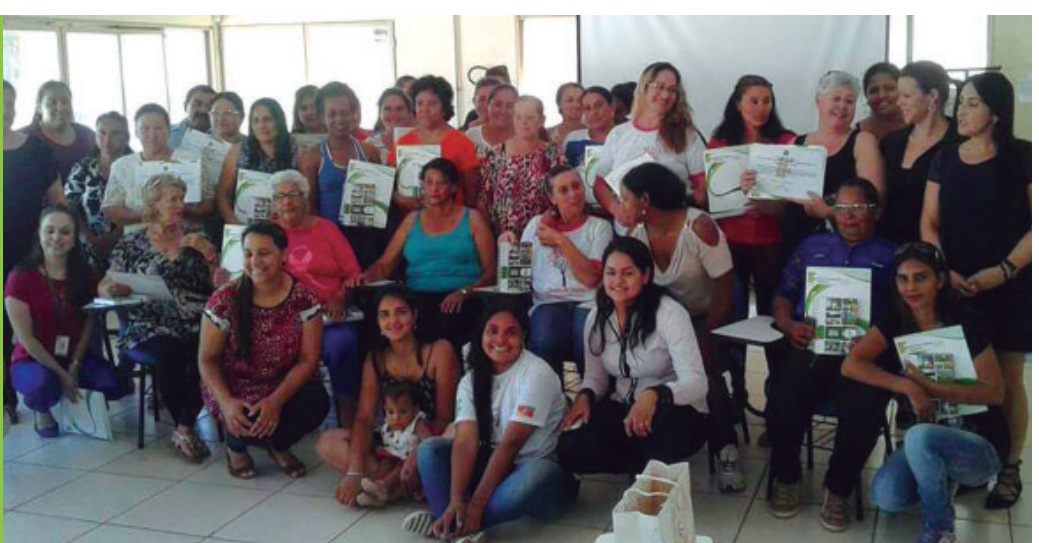

Figura 18: Entrega de agendas do IFFar a uma das alunas.

Fonte: Dados desta Pesquisa.

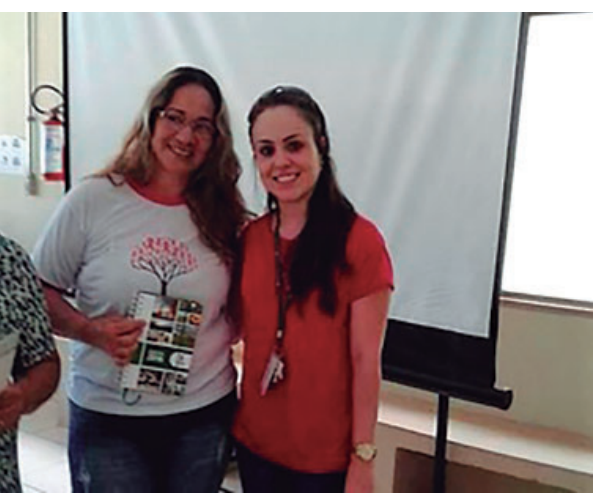




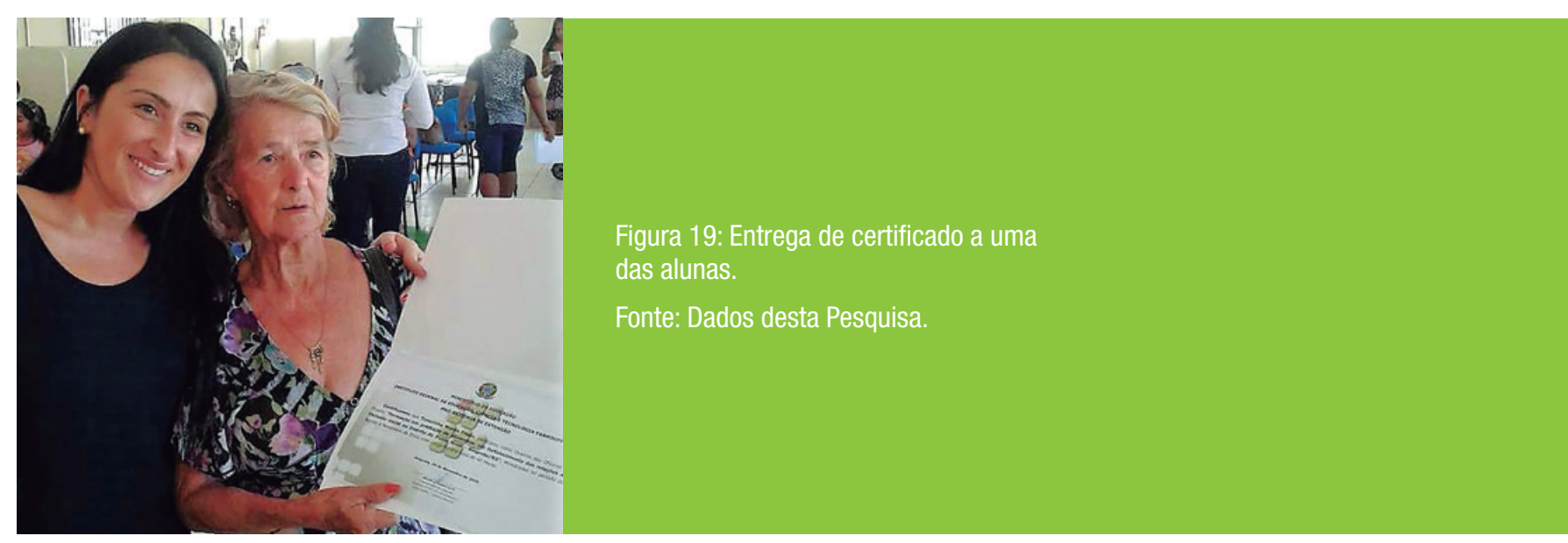

\subsection{Contribuições da atividade de extensão}

Ao longo da ação de extensão foram discutidos assuntos relacionados principalmente à produção de alimentos, ou seja, como produzir estes alimentos seguros ao consumidor através de práticas higiênico-sanitárias adequadas; como garantir a segurança do manipulador de alimentos por uso de equipamentos de proteção individual, entre outros; como descartar corretamente 0 resíduo gerado a fim de garantir a preservação do meio ambiente em que se vive. Foi discutido ainda sobre a importância desta associação que produz (ou não), como o tema foco do projeto de extensão "o importante papel destas mulheres na comunidade em que se encontram".

De acordo com Valente (2002), 0 ato de se alimentar é uma das atividades humanas que mais reflete a enorme riqueza do processo histórico de construção das relações sociais que se constituem no que se pode chamar de "humanidade" e está intrinsecamente ligado à identidade cultural de cada povo ou grupo social. Assim, a produção para o autoconsumo em determinada localidade é uma forma de internalizar recursos locais, estimular a segurança alimentar, ampliar o leque de estratégias sob o qual está assentada a continuidade do grupo familiar e assim minimizar a sua vulnerabilidade.

É uma forma de economização na medida em que aperfeiçoa a utilização dos fatores de produção (terra e força de trabalho) e dos recursos financeiros; restabelece a coprodução entre homem, natureza e trabalho, potencializando os recursos locais; possibilita atender a demanda alimentar e a realização de valores de troca em virtude da característica da alternatividade; alimenta relações de sociabilidade e reciprocidade contribuindo para a coesão da estrutura social; e fortalece a identidade social dos agricultores, conferindo legitimidade e reconhecimento perante os demais (GRISA, 2007).

De acordo com Cunha (2017), em entrevista à Caminho Aberto - Revista de Extensão do Instituto Federal de Santa Catarina, um dos principais papeis da extensão é a inclusão social de uma determinada comunidade. Ou seja, quanto maior a qualificação, mais chances de colocação no mercado de trabalho e, consequentemente, melhor remuneração e contribuição ao desenvolvimento da localidade. Os autores do presente trabalho acreditam ter contribuído com a qualificação de pelo menos 39 mulheres do distrito do Passo Novo, as quais poderão aplicar o conhecimento adquirido para obtenção de emprego e geração de renda.

Além disso, foi possivel uma aproximação do câmpus com as diversas populações, estimulandose a participação e o comprometimento da equipe (alunos, professores e técnicos administrativos) em dar continuidade a projetos dessa natureza, expandindo as atividades a um número maior de grupos sociais, criando espaços de trocas de conhecimentos com os educandos.

\section{Considerações finais}

Diante do alto índice de permanência, os autores esperam ter contribuído para o aumento do consumo de produtos mais nutritivos, diversificados e de baixo custo; melhoria da participação das mulheres na comunidade relacionada à prática alimentar e, principalmente, com a geração 
de renda e, consequentemente, da qualidade de vida de famílias da Vila do Passo Novo e dos Assentamentos Novo Alegrete e Unidos pela Terra. De acordo com Mézsáros (2008), construir uma educação para além do capital, potencializando o processo de formação dos indivíduos, permitindo um processo educacional que promova a transformação da sociedade, é extremamente necessário, principalmente para a população em estado de vulnerabilidade. Assim, acredita-se que os cursos ofertados por meio das ações de extensão aqui apresentadas sejam um exemplo concreto dessa transformação descrita por Mézsáros (2008),

Uma das formas que as Universidades e os Institutos Federais possuem para formar um profissional cidadão é a efetiva participação dos discentes na comunidade, ou seja, a Extensão. Segundo Saraiva (2007), através da extensão ao aluno é possibilitada a vivência significativa com a comunidade, o que the proporciona reflexões acerca das grandes questões da atualidade e, consequentemente, uma formação compromissada com as necessidades nacionais, regionais e locais. Portanto, além da expectativa da contribuição para com a comunidade da Vila do Passo Novo e dos assentamentos ali localizados, se presume também ter contribuído com a formação profissional cidadã dos discentes dos cursos de nível Superior e Técnico do Instituto Federal de Educação, Ciência e Tecnologia Farroupilha - Câmpus Alegrete/RS.

Com a presente publicação, os autores esperam divulgar as ações realizadas e instigar a outros docentes e discentes a execução de atividades em prol de comunidades em questões de vulnerabilidade social e, consequentemente, a aproximação entre as comunidades acadêmica e não acadêmica, especialmente, através de uma execução contínua.

\section{Agradecimentos}

As autoras agradecem ao Instituto Federal Farroupilha pelo apoio financeiro; à Associação Tabatinga de Usuários Familiares Amigos da Saúde Mental da Vila do Passo Novo e a todos os servidores e discentes envolvidos na na realização deste trabalho.

\section{Referências}

ABIP - Associação Brasileira da Indústria de Panificação e Confeitaria. Indicadores 2016. Disponivel em: <http://www.abip.org.br/site/wp-content/uploads/2017/02/INDICADORES2017-performance-2016.pdf>. Acesso em: junho de 2018.

CUNHA, J. A inclusão social é um dos principais papeis que a Extensão tem de desempenhar.

Caminho Aberto: Revista de Extensão do Instituto Federal deEducação, Ciência e Tecnologia de Santa Catarina. Ano 4, n. 7, p. 9-12, 2017.

CALGARO, H. F.; ALFONSO, I. A.; ARAÚJO, C. A. M. Projeto horta viva: relato de uma experiência de extensão universitária. Rev. Ciênc. Ext. v. 9, n. 1, p. 150-166, 2013.

CAUVAIN, S. P.; YOUNG, L. S. Tecnologia da panificação. 2. ed. Barueri: Manole, 2009.

GRISA, C. A produção "pro gasto": um estudo comparativo do autoconsumo no Rio Grande do Sul. 2007. 200 p. Dissertação (Mestrado em Desenvolvimento Rural) - Faculdade de Ciências Econômicas, Universidade Federal do Rio Grande do Sul, Porto Alegre, 2007.

IBGE - Instituto Brasileiro de Geografia e Estatística. Dados: Alegrete Rio Grande do Sul RS. Disponível em: <https://biblioteca.ibge.gov.br/visualizacao/dtbs/riograndedosul/alegrete. pdf>. Acesso em: junho de 2018.

MÉSZÁROS, István. A educação para além do capital. São Paulo: Boitempo, 2008.

SARAIVA, J. L. Papel da Extensão Universitária na Formação de Estudantes e Professores.

Brasília Médica. v. 44, n. 3, p. 220-225, 2007. 
VALENTE, F.L.S. Segurança Alimentar e Nutricional: transformando natureza em gente. in: VALENTE, F. L. S. Direito Humano à Alimentação - desafios e conquistas. São Paulo, Cortez Editora, 2002.

WITT, A. T. da S.; SOUZA, P. C. de. Programa de extensão Mulheres SIM: um estudo sobre suas alunas e sua efetividade nos câmpus. Caminho Aberto: Revista de Extensão do Instituto Federal deEducação, Ciência e Tecnologia de Santa Catarina. Ano 3, no 4, p. $72-83,2016$. 